\title{
Phenotypic analysis of c-Kit expression in epithelial monolayers derived from postnatal rat pancreatic islets
}

\author{
Rennian Wang ${ }^{1,2}$, Jinming $\mathbf{L i}^{1}$ and Nina Yashpal ${ }^{1}$ \\ Lawson Health Research Institute, Departments of ${ }^{1}$ Physiology and Pharmacology, and ${ }^{2}$ Medicine, University of Western Ontario, London, Ontario, Canada \\ (Requests for offprints should be addressed to Rennian Wang, Child Health Research Institute, $5^{\text {th }}$ Floor, 800 Commissioners Road, East, Room A5-140, \\ London, Ontario, N6C 2V5, Canada; Email: rwang@uwo.ca)
}

\begin{abstract}
The limitation of available islets for transplantation is a major obstacle for the treatment of diabetes through islet therapy. However, islet monolayers expanded ex vivo may provide a source of progenitor cells and a model to help understand islet development from precursor cell types. The existence of progenitor cells within the islets is highly likely, yet, to date, no fully defined or characterized postnatal stem cell has been isolated, expanded or marked. Our study evaluates the expression of progenitor markers, including the haematopoietic stem cell marker c-Kit, in epithelial monolayers derived from postnatal rat islets through immunofluorescence and RT-PCR, and the ability of precursor-rich monolayers to reform islet-like structures. Islets formed confluent monolayers when cultured on a type I collagen gel which lacked endocrine phenotypes but were positive for cytokeratin 20 and contained an increased proportion of proliferating c-Kit-
\end{abstract}

expressing cells, with the proportion reaching a maximum of $45 \pm 6 \%$ at 8 weeks of culture. Evaluation of transcription factors at the mRNA level revealed constant PDX-1, ngn3 and Pax4 expression, while undifferentiated cell markers, such as Oct4 and $\alpha$-fetoprotein, were also detected frequently after 4 weeks of culture. Changing the extracellular matrix protein to laminin-rich Matrigel, the monolayers re-formed islet-like clusters that secreted insulin in a glucose-responsive fashion. Our data show that islets can be expanded ex vivo to form epithelial monolayers with rich undifferentiating cell populations that are characterized by cells expressing the progenitor markers. These monolayers are capable of extensive proliferation and retain plasticity to form new islet cells, and c-Kitexpressing cells may play an important role in new islet cluster formation.

Journal of Endocrinology (2004) 182, 113-122

\section{Introduction}

A major obstacle of islet transplantation is the limitation of available insulin-producing tissue (Serup et al. 2001). Stem cell biology provides an alternative to whole organ transplantation, as it offers the possibility of repopulating damaged or functionally inadequate tissues with specific cell types expanded in vitro that can restore normal biological activity (Ramiya et al. 2000). However, it is important to find a progenitor cell source for the application of stem cell biology to the treatment of diabetes.

Beta cell neogenesis has been shown to follow streptozotocin treatment in the neonatal rat (Wang et al. 1994), pancreatic duct ligation (Wang et al. 1995) and partial pancreatomy (Bonner-Weir et al. 1993). These regeneration studies provide evidence of the existence of progenitor cells within the ducts, and they also suggest that intra-islet precursors may exist. However, an important question remains - how do we identify precursor cell types? Our in vivo study identified subpopulations of cells within the islets immunopositive for the haematopoietic stem cell marker, c-Kit, and for a neural stem cell marker, nestin, in the pre- and postnatal rat pancreas which decreased in proportion with age, coincident with the appearance and development of endocrine cell types that normally accompany postnatal restructuring of the pancreas (Yashpal et al. 2004). These two candidate precursor markers have been previously described by others to be expressed in the pancreas in a fashion that suggests their role as putative progenitors (Rachdi et al. 2001, Zulewski et al. 2001, Huang \& Teng 2003).

Of these precursor markers, c-Kit, a transmembrane receptor protein whose ligand is stem cell factor (SCF), is of critical importance for early epithelial stem cell differentiation in haematopoiesis and gametogenesis. c-Kit expression in the pancreas has been previously described in the pancreatic ducts (Oberg-Welsh \& Welsh 1996), and it is implicated in the development, function and survival of the islets of Langerhans and, more importantly, in $\beta$-cell 
survival (Welsh et al. 2000). Rachdi et al. reported that Kit mRNA is present in fetal and adult rat islets, and is specifically transcribed in $\beta$ cells (Rachdi et al. 2001), as confirmed by our in vivo study on the developing rat pancreas. It is interesting that only a subpopulation of $\beta$ cells express c-Kit at specific stages in their development (Rachdi et al. 2001, Yashpal et al. 2004). Furthermore, our previous ex vivo examination of the developing rat pancreas (Yashpal et al. 2004) demonstrated that islet development is accompanied by a decrease in the proportion of cells immunopositive for $\mathrm{c}$-Kit during the prenatal to postnatal period of development, the highest expression occurring during the first postnatal week. We also demonstrated that c-Kit positive-cells lack islet hormone coexpression in the postnatal period, revealing their immature morphology.

The shortage of $\beta$-cells has prompted a search for a source of putative progenitors or stem cells and new mechanisms to increase donor $\beta$-cell mass. When islet monolayers form on extracellular matrix from the rat bladder carcinoma cell line $804 \mathrm{G}$, there is an increase in cell numbers but a decrease in islet-cell-specific gene expression (Beattie et al. 1997). Furthermore, islet expansion in monolayer cultures leads to a loss of $\beta$-cell function and senescence (Beattie et al. 2002). Our previous study (Wang et al. 2001) revealed that pancreatic islet isolation interrupts the islet-matrix relationship, induces some apoptosis, and leads to a loss of stability, resulting in transdifferentiation of an islet to a ductal phenotype on type I collagen through cAMP-pathway-dependent mechanisms. These two studies suggest that islet monolayers may be characterized by the expression of undifferentiated cell markers, which, once identified, will ease purification and manipulation of progenitor cell populations under the influence of appropriate environmental cues to re-form islet clusters or islet cell types through differentiation protocols.

The following study examines a mechanism for increasing precursor cell populations by culturing rat pancreatic islets on a matrix of collagen type I and subsequently changing the extracellular environment to promote islet cell reaggregation. Here we have reproduced our previously described transdifferentiation model (Wang et al. 2001) and reveal that during monolayer expansion, the proportion of insulin- and glucagon-expressing cells diminishes - accompanied by an increase in the proportion of c-Kit-expressing cells which can be immunomagnetically sorted and cultured. These monolayers also express signature transcription factors and other progenitor markers revealing the multitude of heterogeneous undifferentiated cell types in culture. This transdifferentiation model may serve to establish future strategies aimed at the subsequent differentiation of islet-like structures from clonally isolated progenitors or reformation of islets directly from expanded heterogeneous cell populations under controlled in vitro conditions.

\section{Materials and Methods}

\section{Islet isolation and culture}

Due to the increasing evidence that islets harbour intraislet progenitors, we isolated 7-day-old pancreata to examine the development and changes in phenotype and morphology of islet cells when cultured on type I collagen matrix. Timed-pregnant Wistar rats were obtained for the isolation of islets on postnatal day 7 (Charles River, Quebec, Canada). All protocols were approved by the Animal Care Committee at the University of Western Ontario, in accordance with the guidelines of the Canadian Council on Animal Care. Rat pancreata were dissected and subjected to collagenase digestion (Sigma), as described previously (Ilieva et al. 1999). Eight postnatal pancreata were used per isolation, and six different islet isolations were performed for each time point in the study. Purification was achieved by a modified Ficoll density gradient (McDaniel et al. 1984). The final preparation consisted of $90 \%$ dithizone-positive structures.

Freshly isolated islets (500 islets per $25 \mathrm{~cm}^{2}$ flask) (Corning, Fisher, Toronto, Ontario, Canada) were placed on type I collagen gel (Wang \& Rosenberg 1999) and cultured in DMEM/F12 (Gibco, Burlington, ON, Canada) serum-free medium supplemented with transferrin $(10 \mu \mathrm{g} / \mathrm{ml})$, insulin $(1 \mu \mathrm{g} / \mathrm{ml})$ and EGF $(10 \mathrm{ng} / \mathrm{ml})$ (Sigma) to promote epithelial monolayer formation (Bonner-Weir et al. 2000, Wang et al. 2001). Cultures were maintained in $95 \%$ air $/ 5 \% \mathrm{CO}_{2}$ at $37{ }^{\circ} \mathrm{C}$, and the medium was renewed on alternate days. The epithelial monolayers were subcultured when the cells had grown to near confluence. Representative islet cultures were examined immediately after isolation (day 0 ), and the derived epithelial monolayers were examined at 1,2, 4 and 8 weeks of the culture period in the following investigations.

\section{Immunocytochemistry and morphometric analysis}

Freshly isolated islets embedded in 2\% agarose were fixed in 4\% paraformaldehyde (PFA) and embedded in paraffin (Wang \& Rosenberg 1999). Islet-derived epithelial monolayers were fixed in situ by 4\% PFA for $10 \mathrm{~min}$ at room temperature. Islet sections, the monolayers and islet-like clusters were immunostained with the primary antibodies as follows: rabbit anti-c-Kit (C-19, Santa Cruz Biotechnology, Santa Cruz, CA, USA), mouse anticytokeratin 20 (CK20, Dako, Mississauga, ON, Canada), mouse anti-human insulin and glucagon, and mouse anti-BrdU (Sigma), rabbit anti-PDX-1 (gift from Dr Wright, University of Vanderbilt, Nashville, TN, USA), rabbit anti-neurogenin 3 (ngn3, gift from Dr German, University of California, San Francisco, CA, USA) and rabbit anti- $\alpha-1$-fetoprotein (Biocare Medical, Walnut Creek, CA, USA), by either the avidin-biotin complex method (Histostain Plus Kit, Zymed, San Francisco, CA, 
Table 1 Characteristics of primers and conditions for RT-PCR

\begin{tabular}{|c|c|c|c|c|c|}
\hline & $\begin{array}{l}\text { Accession } \\
\text { number }^{\mathrm{a}}\end{array}$ & $\begin{array}{l}\text { Primer pair sequence } \\
\text { (sense/antisense) }\end{array}$ & $\begin{array}{l}\text { Location } \\
\text { (nt) }\end{array}$ & $\begin{array}{l}\text { Fragment } \\
\text { size }(b p)\end{array}$ & $\begin{array}{l}\text { Number } \\
\text { of cycles }\end{array}$ \\
\hline \multicolumn{6}{|l|}{ Primer (name) } \\
\hline \multirow[t]{2}{*}{ c-Kit (rat) } & NM022264 & 5'-AGCAAGAGTTAACGATTCCGGAG-3' & 887-909 & 344 & 33 \\
\hline & & 5'-CCAGAAAGGTGTAAGTGCСТCСТ-3' & $1208-1230$ & & \\
\hline \multirow[t]{2}{*}{ PDX-1 } & X74342 & 5'-CCACCСCAGTTTACAAGCTC-3' & 418-437 & 325 & 33 \\
\hline & & 5'-TGTAGGCAGTACGGGTCCTC-3' & $723-742$ & & \\
\hline \multirow[t]{2}{*}{ ngn3 } & U76208 & 5'-TGGCGССТСАТСССТTGGATG-3' & $161-181$ & 160 & 33 \\
\hline & & 5'-CAGTCACCСАСТTCTGCTTCG-3' & $300-320$ & & \\
\hline \multirow[t]{2}{*}{ Pax4 } & AF053103 & 5'-TGGCTTTCTGTCCTTCTGTGAGG-3' & $10-32$ & 242 & 30 \\
\hline & & 5'-TCCAAGACTCCTGTGCGGTAGTAG-3' & $228-251$ & & \\
\hline \multirow[t]{2}{*}{ Insulin } & NM000207 & 5'-TCACACCTGGTGGAAGCTC-3' & $141-159$ & 179 & 28 \\
\hline & & 5'-ACAATGCCACGСТTCTGC-3' & $302-319$ & & \\
\hline \multirow[t]{2}{*}{ Insulin I } & NM019129 & 5'-ATGGCCCTGTGGATGCGCTT-3' & $1-20$ & 331 & 30 \\
\hline & & 5'-TAGTTGCAGTAGTTCTCCAG-3' & $313-331$ & & \\
\hline \multirow[t]{2}{*}{ Insulin II } & NM019130 & 5'-ATGGCCСТGTGGATCCGCTT-3' & $1-20$ & 243 & 30 \\
\hline & & 5'-TGCCAAGGTCTGAAGGTCAC-3' & $224-243$ & & \\
\hline \multirow[t]{2}{*}{ Glucagon } & Z46845 & 5'-CAGAGGAGAACCCCAGATCA-3' & $106-125$ & 202 & 33 \\
\hline & & 5'-TCATGACGTTTGGCAAGTT-3' & $292-307$ & & \\
\hline \multirow[t]{2}{*}{$\beta$-actin } & X00351 & 5'-GACGGGGTCACCCACACTGTGCCCATCTA-3' & 510-538 & 660 & 28 \\
\hline & & 5'-CTAGAAGCATTTGCGGTGGACGATGGAGG-3' & $1141-1169$ & & \\
\hline
\end{tabular}

${ }^{a}$ Genebank accession number for the sequences used in designing the primers.

USA) or immunofluorescence, as described previously (Wang \& Rosenberg 1999). The sections were incubated overnight at $4{ }^{\circ} \mathrm{C}$ with the appropriate dilution of primary antibody. To evaluate cell proliferation, freshly isolated islets and islet-derived epithelial monolayers were incubated with $10 \mu \mathrm{M}$ 5-bromo-2'-deoxyuridine (BrdU, Sigma), followed by immunostaining for BrdU (Wang et al. 1994). Double immunofluorescence staining was performed to identify coexpression of phenotypes in islet-derived epithelial monolayers and islet-like clusters. Fluorescent secondary antibodies obtained from Jackson Immunoresearch Laboratories (West Grove, PA, USA) were fluorescein (FITC) antimouse or antirabbit antibodies $(1: 100)$, or rhodamine (TRITC) antirabbit or antimouse antibodies $(1: 100)$. For identification of alkaline phosphatase expression within the islet-derived epithelial monolayers, histological staining was performed with NAMP/fast blue, and the nuclei were counterstained with nuclear fast red (Sigma). Double-labelled images were recorded by a Lecia DMIRE2 fluorescence microscope with the Openlab image software (Improvision, Lexington, MA, USA). Negative controls included the omission of the primary antibodies and preabsorption of the antiserum with excess peptides where available.

The number of cells expressing c-Kit and BrdU labelling index was determined with a Carl Zeiss transmitted light microscope connected to computer-assisted image analysis software (Northern Eclipse version 2·0, Empix Imaging Co., Mississauga, ON, Canada). For each time point, at least 1000 cells were counted, and each time point was repeated six times. The data were expressed as a percentage of the total number of cells counted and compared by Student's $t$-test, with differences considered to be statistically significant when $P<0 \cdot 05$.

Reverse transcription and polymerase chain reaction (RT-PCR)

Total RNA was extracted from freshly isolated islets, islet-derived epithelial monolayers and reformed islets with the RNAqueous-4 PCR kit (Ambion, Austin, TX, USA). cDNAs were synthesized from $2 \mu \mathrm{g}$ total RNA, using oligo(dT) as a primer with the SuperScript First Strand Synthesis System (Invitrogen). Subsequent PCR assays were performed, and the PCR oligonucleotide primers used to amplify specific cDNA fragments are listed in Table 1. The amplified products were analyzed on $1.5 \%$ agarose gels and visualized by ethidium bromide staining. Sequencing of PCR products for verification was done in the Robarts Research Institute Core Molecular Biology Facility (London, ON, Canada).

\section{Differentiation culture}

To determine whether islet-like structures could be re-formed in vitro from progenitor cell-enriched monolayers, cells were replaced on Matrigel-coated chamber slides (Lab-Tek Chamber Slides, four-well; Nunc, Naperville, IL, USA) and cultured with DMEM:F12 (Sigma) medium containing 10\% fetal bovine serum (FBS), keratinocyte growth factor (KGF, $50 \mathrm{ng} / \mathrm{ml}$; R\&D System Inc., Minneapolis, MN, USA) to induce the islet cell differentiation (Bonner-Weir et al. 2000). Isletderived epithelial monolayers grew as islet-like clusters, 
adherent on Matrigel and were examined after 7 days of differentiation in culture by immunofluorescent staining and RT-PCR analysis.

\section{Purification of c-Kit-positive cells}

To purify a population of c-Kit-expressing cells from the islet-derived epithelial monolayers, immunomagnetic c-Kit/FITC-microbeads (Chemicon, Temecula, CA, USA) were used to isolate a population of c-Kit-positive cells through a magnetic column (Miltenyl Biotec., Auburn, CA, USA). A purity of 70\% c-Kit-expressing cells was achieved following purification, and the differentiation culture as described above was followed to determine the potential of c-Kit-expressing cells to re-form islet-like clusters.

\section{Measurement of insulin secretion}

Insulin content and basal insulin release from islet-derived epithelial monolayers or reformed islet-like clusters were measured using a rat insulin ELISA kit (DRG Diagnostic Inc., Mountainside, NJ, USA) with a sensitivity of $0 \cdot 15 \mathrm{ng} / \mathrm{ml}$. The DNA content of the samples was determined alongside the insulin content, which was calculated as $\mathrm{ng} / \mu \mathrm{g}$ DNA. Glucose responsiveness of re-formed islet-like clusters was examined with an acute glucose challenge, as described previously (Wang \& Rosenberg 1999), on day 7 of the differentiation culture. Islet-like clusters were incubated in RPMI1640 medium (Sigma) containing $22 \mathrm{mM}$ glucose plus $50 \mu \mathrm{M}$ IBMX, and insulin secretion was expressed as ng/well. A static glucose stimulation index was calculated by dividing the insulin output from the high glucose plus IBMX incubation by the insulin output during low glucose $(2 \cdot 2 \mathrm{mM})$ incubation (Wang \& Rosenberg 1999).

\section{Results}

Patterns of c-Kit expression and proliferation in islet-derived epithelial monolayers

Islets cultured on a type I collagen gel spread to form epithelial monolayers, as demonstrated by their immunoreactivity for the epithelial cell marker, cytokeratin 20 (Fig. 1A), and expression of insulin and glucagon was diminished during the transdifferentiation process (Fig. 1C, D), as observed previously (Wang et al. 2001). Interestingly, staining for the progenitor cell marker c-Kit increased progressively over the culture period (Fig. 1B). Quantitative analysis demonstrated that the percentage of c-Kit-positive cells $(9 \pm 3 \%$ at day 0$)$ reached a maximum at $45 \%$ after 8 weeks of culture $(P<0 \cdot 001$, Fig. 2 A). A constant proportion of c-Kit-expressing cells could be maintained in long-term culture as well. The islet-derived epithelial monolayers were highly proliferative, demonstrating up to a $41 \pm 5 \%$ BrdU labelling index after 4 weeks of culture (Fig. 2B), with no subsequent significant change in the labelling index after 4 weeks in vitro. Double immunostaining for BrdU and c-Kit at 4 weeks of culture showed that $21 \pm 3 \%$ of c-Kit-positive cells were BrdU labelled.

Patterns of $m R N A$ expression of $c$-Kit, endocrine cell markers and transcription factors in islet-derived epithelial monolayers

The formation of islet-derived epithelial monolayer was preceded by decreased insulin and glucagon mRNA expression (Fig. 3), paralleling their loss at the protein level (Fig. 1). On the other hand, the expression of c-Kit mRNA as determined by RT-PCR paralleled the increase in their protein levels. The progression in morphology from progenitor epithelial cell to functional endocrine cell is defined and controlled intrinsically by the expression of a series of transcription factors such as PDX-1, ngn3 and Pax4. These factors provide a distinct signature for the differentiation of each endocrine cell type and were also detected throughout the culture period (Fig. 3) (Sander \& German 1997, Dohrmann et al. 2000, Schwitzgebel et al. 2000).

Expression of undifferentiated cell markers and coexpression patterns in islet-derived epithelial monolayers

After 4 weeks of culture, the monolayers frequently stained for $\alpha$-fetoprotein (Fig. 4A) and alkaline phosphatase (Fig. 4B). This increase was associated with the mRNA expression of the transcription factor Oct4 (Fig. 4C). All of these markers have been previously identified as undifferentiated cell markers (Lumelsky et al. 2001).

To identify coexpression of immunophenotypes in isletderived epithelial cells, dual immunofluorescent staining was performed for the epithelial cell marker CK20 with c-Kit or transcription factors. Coexpression of CK20 with either PDX-1 (65.9 $\pm 5 \cdot 6 \%)$, or c-Kit $(33 \cdot 2 \pm 9 \cdot 2 \%)$ was frequently observed in monolayers during the expansion of c-Kit-expressing cells after 8 weeks in culture (Fig. 5). Although the number of ngn3-positive cells was quite low, the coexpression of ngn3 with CK20 was found throughout the culture period $(1 \cdot 6 \pm 0 \cdot 2 \%)$ (Fig. 5).

Differentiation of islet-derived epithelial monolayers and $\mathrm{c}-\mathrm{Kit}^{+}$ cells into hormone-secreting islet-like clusters

For examination of the potential of islet-like structures to be re-formed from expanded epithelial monolayers in vitro based on the extensive appearance of heterogeneous populations of undifferentiated cells types, a laminin-rich extracellular matrix, Matrigel, was utilized to monitor islet cell differentiation (Bonner-Weir et al. 2000). Cells adhered and reformed islet-like clusters on Matrigel within 

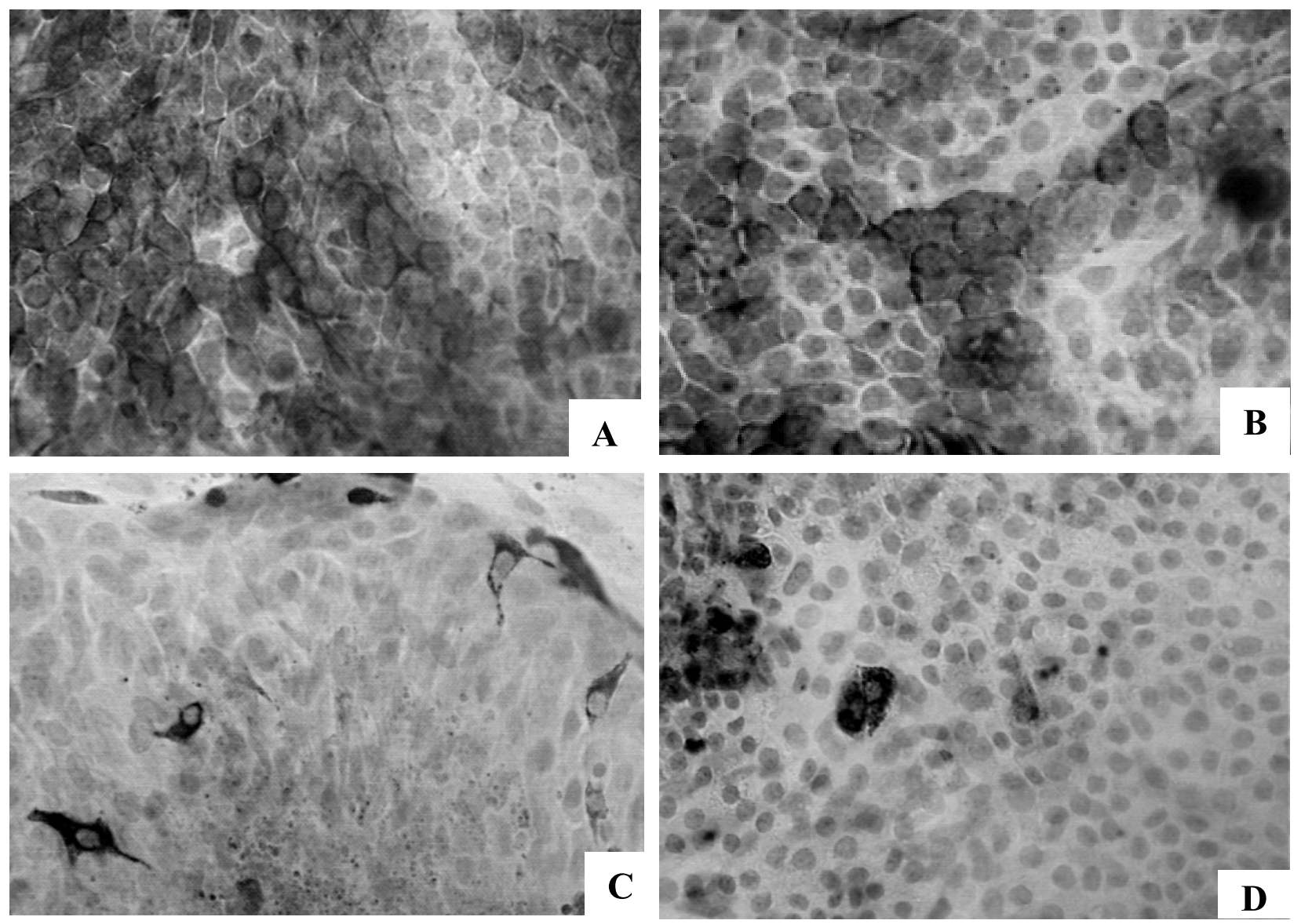

Figure 1 Phenotypic characterization of islet-derived epithelial monolayers cultured on type I collagen gel for 4 weeks. Immunostaining for the epithelial cell marker, cytokeratin 20 (A), the putative endocrine progenitor cell marker c-Kit (B), and the endocrine hormones insulin $(C)$ and glucagon (D). Original magnification $\times 400$.

a week, with 17-fold and 2-fold significant increases in the proportion of insulin- and glucagon-immunopositive cells respectively in comparison to undifferentiated monolayers (Table 2). Their mRNA levels detected by RTPCR were also observed to increase (Fig. 6A). In contrast, the presence of c-Kit immunoreactivity and mRNA decreased over the 1-week differentiation culture period, with a $40 \%$ decrease in c-Kit-expressing cells (Table 2, Fig. 6A). Interestingly, coexpression of c-Kit with insulin, which is frequently observed in fetal rat islet cell development (Yashpal et al. 2004), was also detected after 1 week (Fig. 6B). Comparison of total cellular insulin content and insulin release before and after islet-like cluster formation showed that the clusters undergo progressive maturation until day 7 in the differentiation culture. The total insulin content of islet-like cluster cells increased 8-fold over that of islet-derived epithelial monolayers (Table 3), and basal insulin release rate was also detectable after 7 days in culture (Table 3). Moreover, in response to a glucose challenge, the newly formed isletlike clusters showed a $2 \cdot 5$-fold increase in insulin secretion after cells were exposed to $22 \mathrm{mM}$ glucose plus $50 \mu \mathrm{M}$ IBMX.

Given that a high proportion of c-Kit-expressing cells were present in the islet-derived epithelial monolayers, we next examined the potential of c-Kit expression cells to re-express insulin and form islet-like clusters. c-Kitpositive-cells were immunomagnetically sorted and expanded on a type I collagen gel (Fig. 6C). Subsequently, after expansion, the extracellular matrix was replaced by Matrigel, and the mRNA expression of insulin and glucagon was examined. RT-PCR analysis of c-Kit ${ }^{+}$cells cultured on type I collagen revealed that no detectable insulin or glucagon signals were present; however, c-Kit positive-cells later cultured on Matrigel expressed insulin and glucagon mRNA, although the expression was weak. Furthermore, c-Kit mRNA expression was greatly diminished when Matrigel was used (Fig. 6D). 

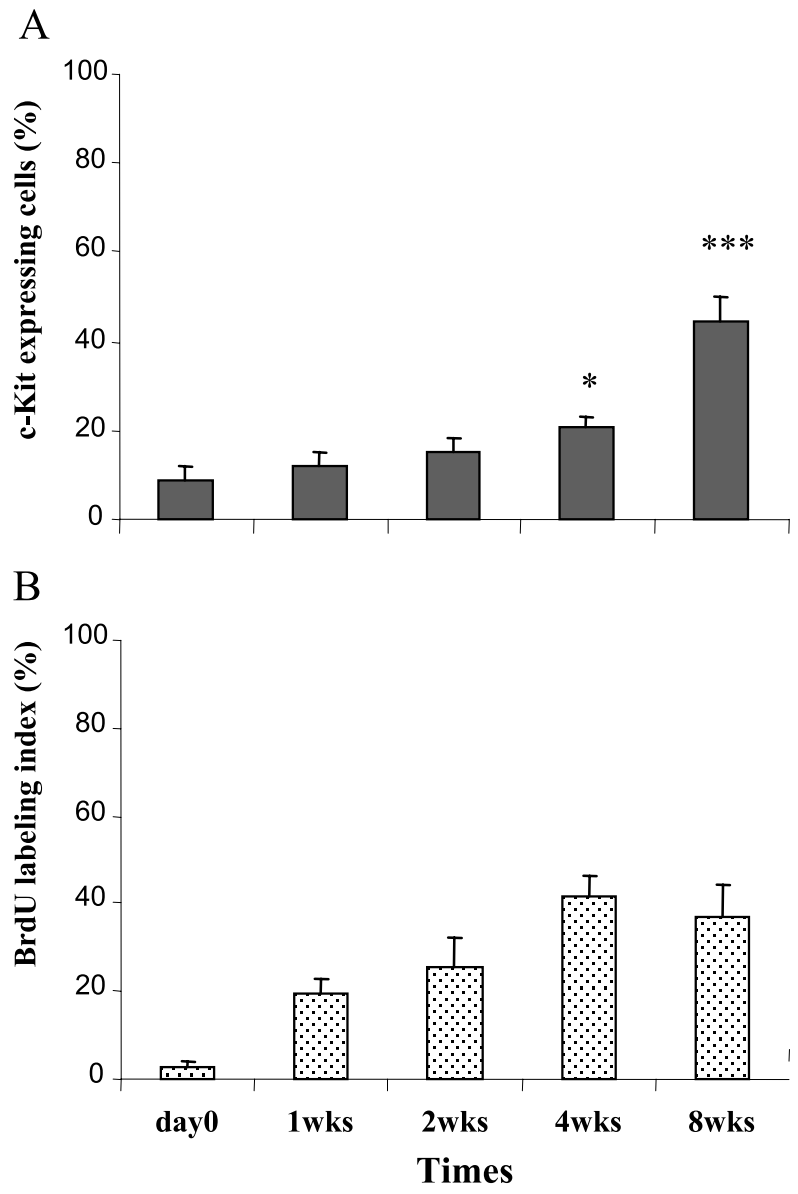

Figure 2 Quantitative analysis of c-Kit-expressing cells within islet-derived epithelial monolayers (A), and the BrdU labelling index (B) of the monolayers. ${ }^{*} P<0 \cdot 05,{ }^{* * *} P<0 \cdot 001$ vs day 0 control.

\section{Discussion}

Our study examines the development and expression of the putative islet progenitor marker, c-Kit, in epithelial monolayers derived from isolated postnatal rat islets and intra-islet progenitor plasticity. Using an islet transdifferentiation model, our data show that highly enriched proliferating populations of cells expressing c-Kit and signature pancreatic transcription factors can be expanded on type I collagen in vitro, and these monolayers retain the ability to give rise to new islets. Furthermore, c-Kitexpressing cells could be maintained in long-term culture, and the appearance of other undifferentiated markers highlights the heterogeneous populations of intra-islet progenitors that are present in the monolayers. This experimental model and phenotypic analysis of putative intra-islet progenitors is a fundamental starting point for experimental approaches that utilize islets as a source for progenitor cells and for a novel approach to the expansion,

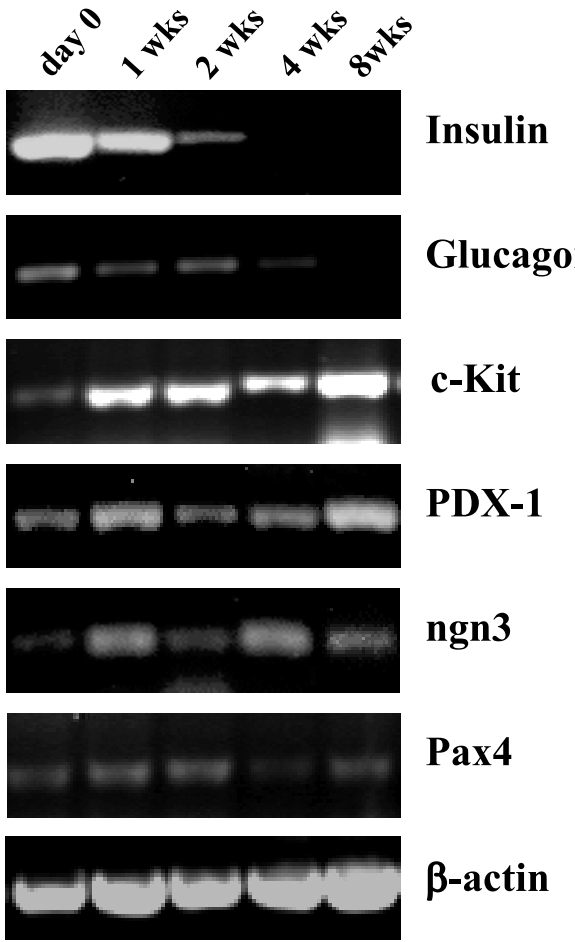

Figure 3 RT-PCR analysis of c-Kit mRNA, endocrine signals and developmental transcription factors in islet-derived epithelial monolayers during the culture period.

clonal isolation and manipulation of precursor cells into islet cell types.

Our previous findings, in agreement with those of others, confirm that the early postnatal rat pancreas retains a population of c-Kit-positive precursor cells within the islets (Oberg-Welsh \& Welsh 1996, Welsh et al. 2000, Rachdi et al. 2001, Yashpal et al. 2004). Islets cultured on type I collagen matrix rapidly adhered to the matrix, and spread to form a monolayer of cytokeratin-positive epithelial cells. Epithelial monolayer formation was preceded by two events, the loss of insulin and glucagon phenotypes, and an increase in cells expressing c-Kit. The populations of c-Kit-expressing cells were maintained at relatively high and constant levels throughout 8-week culture, as determined by immunocytochemistry and RT-PCR.

Examining gene expression of transcription factors related to endocrine cell development, we found constant expression of PDX-1, ngn3 and Pax4, further indicating that the cells present in the monolayers are fetal-like. Ngn3 is a developmental transcription factor and proendocrine gene that operates downstream of PDX-1 specifically to control embryonic pancreas and endocrine cell differentiation ( $\mathrm{Gu}$ et al. 2002) by activating the NeuroD/ 32 promoter. The expression of these two pancreatic transcription factors reveals additional immaturity of phenotypes. Additionally, Pax4, which acts downstream 
A

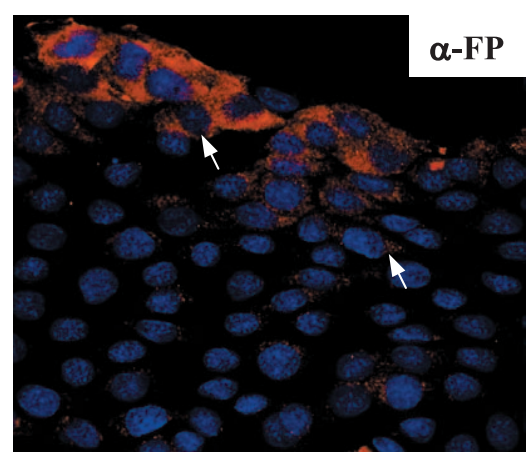

B
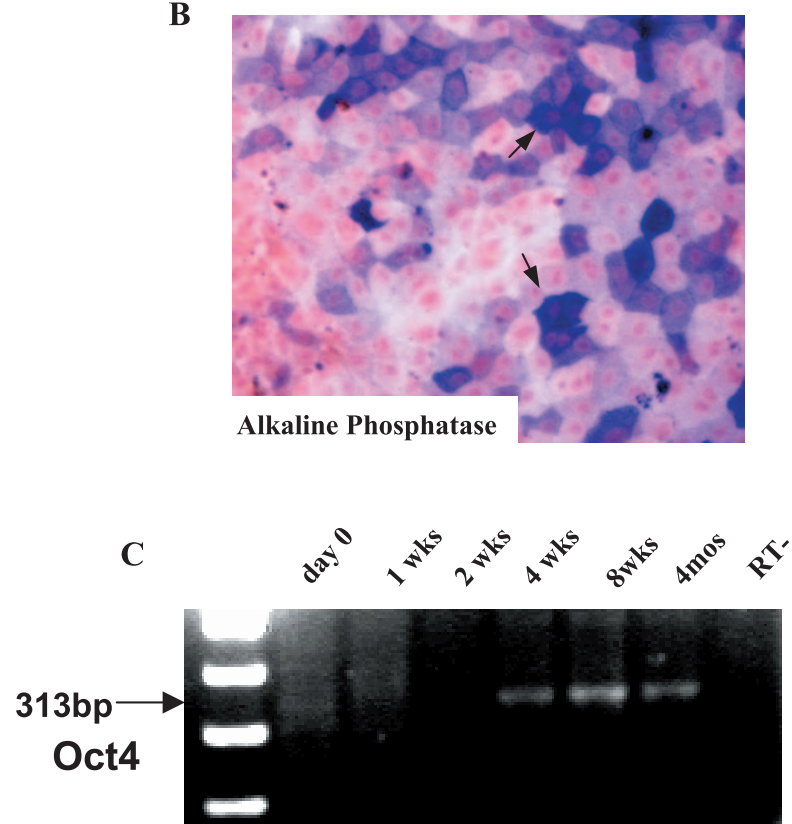

Figure 4 (A) Immunofluorescent analysis for $\alpha$-fetoprotein (TRITC), (B) histochemical staining for alkaline phosphatase in islet-derived epithelial monolayers at 4 weeks of culture and (C) RT-PCR analysis of Oct4 expression in the monolayers with time in vitro. (A) Nuclei were stained by DAPI (blue colour; arrows indicate the positive cells), and (B) cytoplasm stained as blue for alkaline phosphatase and nuclei was counterstained by nuclear fast red. Original magnification $\times 400$.

of $\mathrm{NeuroD} / \beta 2$ to drive $\beta$-cell differentiation (GrapinBotton A et al. 2001), is also expressed constantly throughout the culture period, suggesting that expression of these genes throughout the culture period may indicate the potential of monolayer cells under appropriate conditions also to be driven down a $\beta$-cell developmental pathway. Other markers of undifferentiated cells, such as Oct4, $\alpha$-fetoprotein and alkaline phosphatase (Lumelsky et al. 2001), in the culture period were also detected. Taken together, our data demonstrate that islet-derived epithelial monolayers are enriched with immature cell types, which express not only immunoreactive stem cell markers, including c-Kit, $\alpha$-fetoprotein and alkaline phosphatase, but also mRNA of transcription factors reminiscent of the fetal pancreas and important in islet development.

Postnatal islets have a low proliferative capacity; however, our expanded c-Kit-positive monolayers reveal that highly proliferative cell populations predominate in vitro. Beattie et al. have revealed that monolayers derived from islets increase in cell number, an effect attributed to an increased proportion of proliferative cells. Such a mitogenic effect is also characteristic of precursor cells.

Coexpression studies of the monolayer cells demonstrated frequent colocalization of c-Kit, PDX-1 or ngn3 with cytokeratin 20 , suggesting that these particular cells may represent epithelial precursor cells that are essential for proper $\beta$-cell development. Unfortunately, we could not confirm or exclude the idea that the c-Kit cell population is the same as PDX-1- or ngn3-expressing cells, as the available antibodies were produced in the same animal species.

To address the potential of these islet-derived monolayers to differentiate and re-form islet clusters, monolayers were transferred to Matrigel. Transfer of monolayers was marked by the emergence of clusters immunoreactive for both insulin and glucagon; however, there was a marked decrease in the proportion of c-Kit-expressing cells. It has been documented that c-Kit expression is an intermediate step in the differentiation of $\beta$-cells (Rachdi et al. 2001, Yashpal et al. 2004). These results suggested that the disappearance of c-Kit expression may coincide with $\beta$-cell appearance such that mature $\beta$-cells may derive from these c-Kit-expressing cell populations. We therefore purified c-Kit ${ }^{+}$cells and demonstrated that $\mathrm{c}-\mathrm{Kit}^{+}$cells potentially contribute to the process of new islet cluster formation because c-Kit+ cells which lack insulin and glucagon mRNA expression can be induced to upregulate gene transcripts of both these hormones under differentiation protocols. Clustered cells, but not epithelial monolayers, were able to secrete insulin and respond to a glucose challenge. Although the insulin response to glucose stimulation suggests these are mature $\beta$ cells, the amount of insulin content and the number of insulin-expressing cells in the re-formed islet-like clusters are lower than those of freshly isolated islets (Bonner-Weir et al. 2000). Further studies will be necessary to develop suitable microenvironments in vitro to optimize $\beta$-cell differentiation and proliferation, and enhance insulin production.

On a practical level, these studies offer a mechanism to search for and expand precursor cells from islets themselves. We have demonstrated that a combination of growth factor and extracellular cues promotes the expansion of precursor cell populations. The appropriate change in the extracellular environment subsequently promotes islet reaggregation, and enhances the expression of the insulin gene, insulin secretion and insulin-expressing cell proportions, while a decrease in the population of progenitor marker-expressing cells is observed. This model is more feasible since monolayers derived from whole islets 

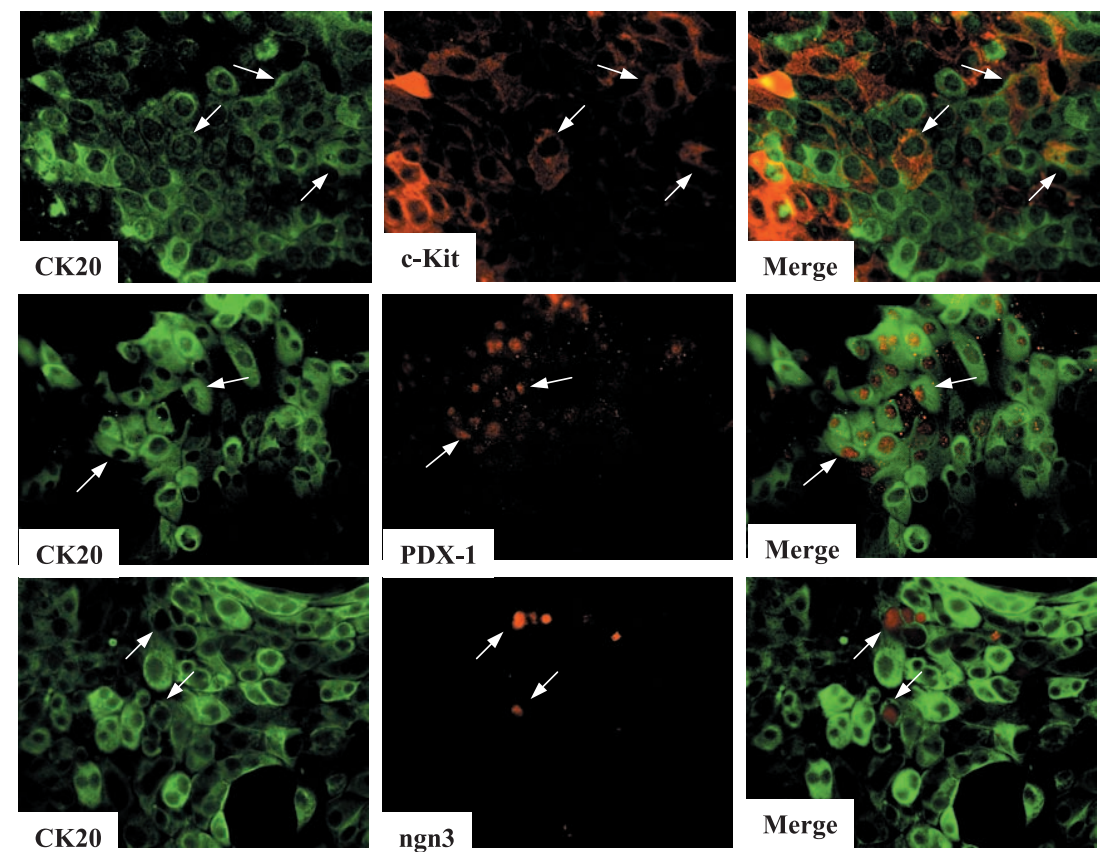

Figure 5 Coexpression of CK20 (FITC) with c-Kit, PDX-1 and ngn3 (TRITC) in islet-derived epithelial monolayers at 2 months of culture determined by double-immunofluorescence staining (arrows indicate the colocalization; original magnification $\times 400$ ).

may circumvent the need to elucidate necessary cell-cell interactions or paracrine signalling that can control differentiation of progenitor cells types. Our study, in which cKit-expressing cells have been purified through immunomagnetic cell sorting, reveals that pure cell populations can be selected from these monolayers, with a purity of $70 \%$. The ex vivo expansion of c-Kit-expressing cells in our defined differentiation culture promoted insulin and glucagon mRNA expression, suggesting that c-Kit progenitor populations have the potential of forming new $\beta$ - and $\alpha$-cells. However, the purified cells show weak glucagon and insulin mRNA expression, suggesting that alone sorted cells may not form functionally adequate $\beta$-cells. Instead, the necessary trophic support, cell-cell interactions and paracrine factors that may be offered through expansion of the entire islet may be a more practical way of reforming the islet cell mass. All in all, this study shows that considerable islet cell plasticity is present in the postnatal rat pancreas, as demonstrated by the capacity to form epithelial cells alone, and presents an exciting new experimental model for the generation of islet clusters from whole islet populations, or for providing a source to isolate progenitor cell types and examine the cell lineage commitment and differentiation into islet cells.

Table 2 Comparison of endocrine and progenitor cell proportions in freshly isolated islets, islet-derived monolayers and differentiated cultures

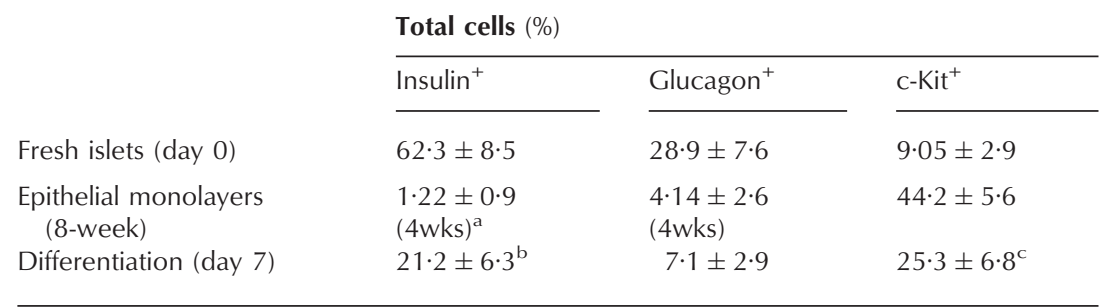

Data presented are means \pm s.D. The results were reproduced in six independent experiments.

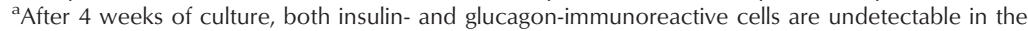

monolayers. Statistical analysis showed significant differences between the cells in epithelial monolayers and after the differentiation culture.

${ }^{\mathrm{b}} \mathrm{P}<0.001$

${ }^{c} P<0 \cdot 01$. 
$\mathbf{A}$

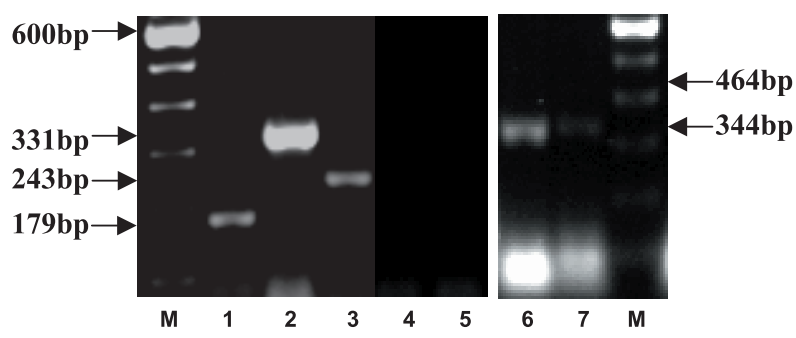

B

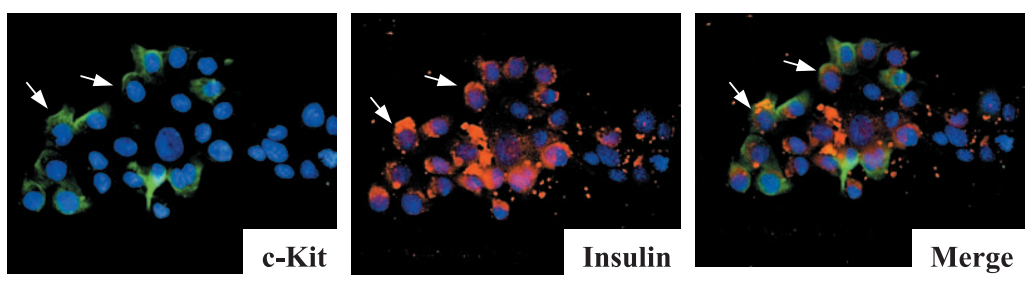

C

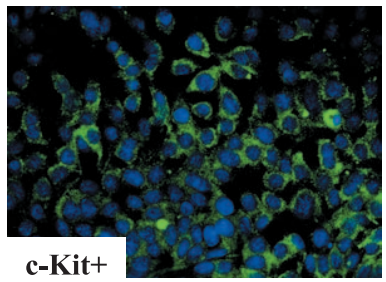

D
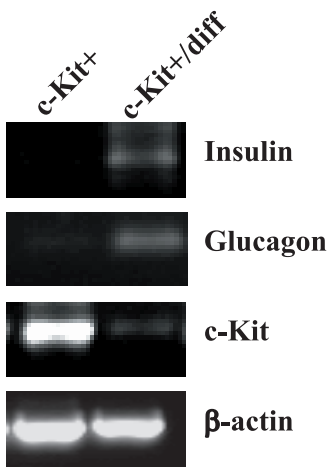

Figure 6 (A) RT-PCR analysis of preproinsulin (lanes 1 and 4), insulin I (lane 2), insulin II (lane 3) and c-Kit (lanes 6 and 7) mRNA expression before (lanes 4 and 6 monolayers) culture on type I collagen and after (lanes 1-3 and 7 islet-like clusters) culture on Matrigel (M: DNA ladder; lane 5: RT negative). (B) Double immunofluorescence for c-Kit (FITC) with insulin (TRITC) was observed in a reformed islet-like cluster; arrows indicate the coexpressing phenotypes. Nuclei were counterstained by DAPI $(\times 400)$. (C) Positively selected $\mathrm{c}-\mathrm{Kit}^{+}$cells cultured on type I collagen gel for 1 week with c-Kit immunostaining ( $\times 400$ ). (D) RT-PCR analysis of preproinsulin and glucagon, as well as c-Kit mRNA in c-Kit ${ }^{+}$ monolayers $\left(\mathrm{c}-\mathrm{Kit}^{+}\right)$and $\mathrm{c}-\mathrm{Kit}^{+}$differentiated islet-like clusters (c-Kit ${ }^{+} /$diff) on Matrigel.

\section{Acknowledgements}

This work was supported by grants from the Canadian Institute of Health Research (CIHR). Dr Wang is sup- ported by a University Faculty Award from the Natural Science and Engineering Research Council of Canada (NSERC). The authors are grateful to Dr D J Hill, a director of the Lawson Health Research Institute, and

Table 3 Islet-derived epithelial monolayers redifferentiate, forming islet-like clusters to store and release insulin

\begin{tabular}{|c|c|c|c|}
\hline & $\begin{array}{l}\text { Basal insulin } \\
\text { release }(\mathrm{ng} / \mathrm{ml})\end{array}$ & $\begin{array}{l}\text { Insulin content } \\
(\mathrm{ng} / \mu \mathrm{g} \mathrm{DNA})\end{array}$ & $\begin{array}{l}\text { Static glucose- } \\
\text { stimulation index }\end{array}$ \\
\hline Epithelial monolayers & ND & $0.04 \pm 0.02$ & ND \\
\hline 7 days of differentiation & $2 \cdot 7 \pm 1 \cdot 5$ & $0 \cdot 32 \pm 0 \cdot 07$ & $2 \cdot 49 \pm 0 \cdot 22$ \\
\hline
\end{tabular}

Data presented are means \pm S.D. The results were reproduced in six independent experiments. ND, not detected. 
Dr C Goodyer (Research Institute of Montreal Children's Hospital, McGill University) for their critical comments on the manuscript.

\section{References}

Beattie GM, Cirulli V, Lopez AD \& Hayek A 1997 Ex Vivo expansion of human pancreatic endocrine cells. Journal of Clinical Endocrinology and Metabolism 82 1852-1856.

Beattie GM, Montgomery AM, Lopez AD, Hao E, Perez B, Just ML, Lakey JR, Hart ME \& Hayek A 2002 A novel approach to increase human islet cell mass while preserving $\beta$-cell function. Diabetes $\mathbf{5 1}$ 435-439.

Bonner-Weir S, Baxter LA, Schuppin GT \& Smith FE 1993 A second pathway for regeneration of adult exocrine and endocrine pancreas. Diabetes 42 1715-1720.

Bonner-Weir S, Taneja M, Weir G, Tatarkiewicz, Song KH, Sharma A \& O'Neill JJ 2000 In vitro cultivation of human islets from expanded ductal tissue. PNAS 97 7999-8004.

Dohrmann C, Gruss P \& Lemaire L 2000 Pax genes and the differentiation of hormone-producing endocrine cells in the pancreas. Mechanisms of Development 92 47-54.

Grapin-Botton A, Majithia AR \& Melton DA 2001 Key events of pancreas formation are triggered in gut endoderm by ectopic expression of pancreatic regulatory genes. Genes and Development 15 444-454.

Gu G, Jolanta D \& Douglas AM 2002 Direct evidence for the pancreatic lineage: NGN3+ cells are islet progenitors and are distinct from duct progenitors. Development 129 2447-2457.

Huang H \& Tang X 2003 Phenotypic determination and characterization of nestin-positive precursors derived from human fetal pancreas. Laboratory Investigation 83 539-547.

Ilieva A, Yuan S, Wang R, Agapitos D, Hill DJ \& Rosenberg L 1999 Pancreatic islet cell survival following islet isolation - the role of cellular interactions in the pancreas. Journal of Endocrinology 161 357-364.

Lumelsky N, Blondel O, Laeng P, Velasco I, Ravin R \& McKay R 2001 Differentiation of embryonic stem cells to insulin-secreting structures similar to pancreatic islets. Science 292 1389-1394.

McDaniel ML, Colca JR \& Kitagal M 1984 Islet cell isolation and characterization. In. Methods in Diabetes Research, Vol. 1 Laboratory Methods. eds J Larner, S Pohl. New York, John Wiley, pp. 153-166.

Oberg-Welsh \& Welsh M 1996 Effect of certain growth factors on in vitro maturation of rat fetal islet-like structures. Pancreas 12 334-339.
Rachdi L, Ghazi LE, Bernex F, Panthier JJ, Czernichow P \& Scharfmann R 2001 Expression of the receptor tyrosine kinase KIT in mature $\beta$-cells and in the pancreas in development. Diabetes $\mathbf{5 0}$ 2021-2028.

Ramiya VK, Maraist M, Arfors KE, Schatz DA, Peck AB \& Cornelius JG 2000 Reversal of insulin-dependent diabetes using islet generated in vitro from pancreatic cells. Nature Medicine 6 278-282.

Sander M \& German MS 1997 The beta cells transcription factors and development of the pancreas. Journal of Molecular Medicine $\mathbf{7 5}$ 327-340.

Schwitzgebel VM, Scheel DW, Conners JR, Kalamaras J, Lee JE, Anderson DJ Sussel L, Johnsson JD \& German MS 2000 Expression of neurogenin 3 reveals an islet cell precursor population in the pancreas. Development 127 3533-3542.

Serup P, Madsen OD, Mandrup-Poulsen T 2001. Islet and stem cell transplantation for treating diabetes. British Medical Journal 322 29-32.

Wang R \& Rosenberg L 1999 Maintenance of islet beta-cell function and survival following islet isolation requires re-establishment of the islet-matrix relationship. Journal of Endocrinology 163 181-190.

Wang R, Bouwens L \& Kloppel G 1994. Beta cell proliferation in normal and streptozotocin-treated newborn rats: site, dynamics and capacity. Diabetologia 37 1088-1096.

Wang R, Kloppel G \& Bouwens L 1995 Duct to islet cell differentiation and islet growth in the pancreas of duct-ligated adult rats. Diabetologia 38 1405-1411.

Wang R, Li J \& Rosenberg L 2001. Factors mediating the transdifferentiationof islets of Langerhans to duct epithelial-like structures. Journal of Endocrinology 171 309-319.

Welsh M, Annernan C, Lindholm C, Kriz V, Oberg-Welsh C 2000. Role of tyrosine kinase signaling for beta-cell replication and survival. Upsala Journal of Medical Sciences 105 7-15.

Yashpal N, Li J \& Wang R 2004 Characterization of c-Kit and nestin expression during islet cell development in the prenatal and postnatal rat pancreas. Developmental Dynamics 229 813-825.

Zulewski H, Abraham EJ, Gerlach MJ, Daniel PB, Moritz W, Muller BM, Vallejo M, Thomas MK \& Habener JF 2001 Multipotential nestin-positive stem cells isolated from adult pancreatic islets differentiate ex vivo into pancreatic endocrine, exocrine, and hepatic phenotypes. Diabetes 50 521-533.

Received in final form 26 March 2004

Accepted 31 March 2004

Made available online as an

Accepted Preprint 14 April 2004 